\title{
The Efficiency of Nitrogen Removal in Humus Activated Sludge Process and the Analysis of Dominance Nitrobacteria
}

\author{
Song Weihua ${ }^{a}$, Ren Xiaoshuai ${ }^{a}$ \\ ${ }^{1}$ The City College of Jilin JianzhuUniversity, Changchun 130000, China. \\ aE-mail address: swh_123@163.com
}

Keywords:humus, activated,sludge,process, humus,soil,Nitrogen,removal,bymicroorganism, Nitro bacter

\begin{abstract}
According to compare two kinds of process: conventional SBR and humus activated sludge process, the efficiency of Nitrogen removal was be investigated. The results show that the removal of NH4+-N by the SBR filled with humus soil was be enhanced, the time in nitrification was be shorten. Also, through the invesgation of the microorganism, the quantity of the Nitrobacter in humus activated sludge process was larger than conventional. The results would be the foundation to study ahead.
\end{abstract}

\section{Introduction}

Developing an effective and economic method for nitrogen removal with biological ways is a focal point throughout the world. The organic solid and the dissovled organic matter in the soil particals can be degradate by the soil bacteria. Basic on this mechanics, some foreign researchers studied the microorganism by separating, verificating, enriching the soil bacteria. After fixing the bacteria on the pack. They put the feed into conventional SBR. Under soil bacteria's action, the metabolism of the bacteria was accelerated. In this procedure,the organic pollutant can be decleared, such as nitrogen ,phosphorus and the matter which can produce odor. Stebilization of the sludge can enhance the efficiency of sludge concentration and sludge dewatering. This process was called Humus Activated Sludge Process (HASP) ${ }^{[1]}$. It was used in some foreign countries ${ }^{[1]}$. The main part of HASP is the pack which was filled in the humus soil reactor. The feed can accelerate the metabolism, and react with the activated sludge, also, the pack offers the specific for the growth of the microoganism. Microelement trace element which the bacteria requaires is supplied by the feed, also the active agent and sludge culture was the other fuction. By comparing the bacteria in two kinds of SBR, the result shows that there are some differences between two processes. Obviously, the HASP is better than coventional processes.

\section{Materials and Methods}

\subsection{Experimental condition}

In this research, the Sequential Batch Reactor (SBR) process has been adopted. It has widly used thoughout the world because of its advantages, such as compeletly nutrient removal and has no secondary pollutant, etc. Fill, react, settle, draw, idle were the five steps of a typical SBR. It can achieve anaerobic, anoxia, aerobic environment in one reactor. Comparison experiment was set, one is conventional SBR (R1), and the other is SBR which was packed with humus soil (R2).

$\mathrm{R} 1$ shows in figure 1.It was an acryl glass cylindrical column with $16 \mathrm{~cm}$ of interdiameter and $70 \mathrm{~cm}$ of height. The total effective volum is $12.5 \mathrm{~L}$. R2 shows in figure 2.It has the same SBR with R1, but connects with a humus soil reactor. The humus soil reactor is an acryl glass cylindrical column with $7 \mathrm{~cm}$ of interdiameter and $80 \mathrm{~cm}$ of height. The total volumn after packing the fee is $1.2 \mathrm{~L}$. 


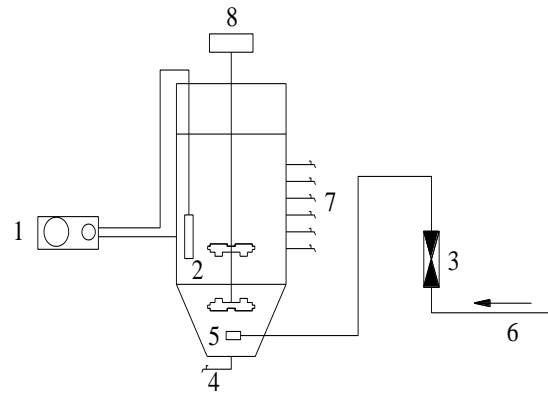

1.Temperature controler 2. Temperature bulb

3. Air rotameter 4.mud pipe 5.aeration head

6. Compressed air 7.outlet8.mixer

Fig. 1 Schematic diagram of SBR (R1)

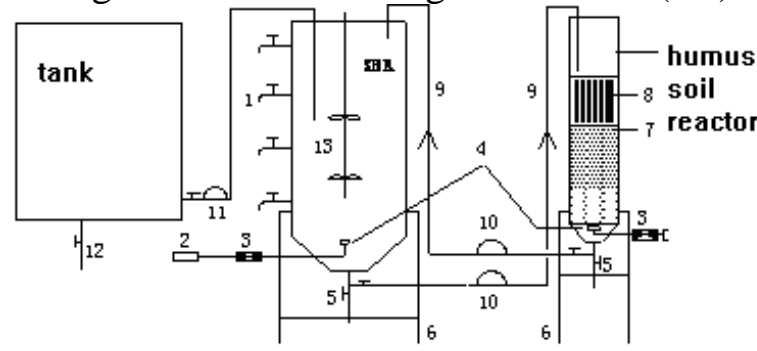

1.Sample connection 2.air pump 3.flowrator

4. Aeration head 5. Mud pipe 6.support frame 7.stone

8.humus soil 9.recycle sludge pipe 10. retern sludge pump

11.pump 12.discharge valve 13.mix plasm

Figure 2 .The systematic diagram of Humus Activated Sludge Treatment process( R2)

\subsection{Parameter conditions}

The parameter shows in table 1 .

Table 1. Main parameter in two process.

\begin{tabular}{|c|c|c|c|}
\hline & & $\mathrm{R} 1$ & $\mathrm{R} 2$ \\
\hline \multicolumn{2}{|c|}{ MLSS (mg/L) } & 4000 & 4000 \\
\hline \multicolumn{2}{|c|}{ Temperature $\left({ }^{\circ} \mathrm{C}\right)$} & $25 \pm 1$ & $25 \pm 1$ \\
\hline \multicolumn{2}{|c|}{ Applied aeration $(\mathrm{m} 3 / \mathrm{h})$} & 0.6 & 0.6 \\
\hline \multirow{3}{*}{ One operation period (10h) } & Aeration time(h) & 6 & 6 \\
\hline & Mixing & 2 & 2 \\
\hline & Settle & 2 & 2 \\
\hline
\end{tabular}

In humus soil reactor, the sludge takes from the SBR was inoculated,the dissovled oxygen maintains $0.5 \mathrm{mg} / \mathrm{L}$ with the aeration. The MLSS keeps $8000 \mathrm{mg} / \mathrm{L}$.In one period,the temperature is $25 \pm 1^{\circ} \mathrm{C}$, aeration time is $12 \mathrm{~h}$, settling for 12 hours. The second morning, $0.6 \mathrm{~L}$ sludge from SBR and the humus soil reactor was exchanged, then begins next cycle of operation .

\subsection{Microorganism Detection [2-6]}

1. The Most Probable Number was used in the experiment .Different nutrient medium was chose and to create anaerobic, aerobic environment to culture bacteria.

2. The sludge which was taken from the reactor in regular time will be settled and detected. The sludge would be diluted and cultured.

\section{Results and Discussion}

R1 and R2 was operated for several periods. After they were stabilized, the experiment would be started by comparing the efficiency of the nitrogen removal between two processes. NH4+-N load is $34 \mathrm{mg} / \mathrm{L}$.

\subsection{Process performance of $\mathrm{R} 1$ and $\mathrm{R} 2$}

Figure 3 shows the profile of $\mathrm{NH}_{4}{ }^{+}-\mathrm{N}$ in $\mathrm{R} 1$ and $\mathrm{R} 2$ reactor. In $\mathrm{R} 2$, the $\mathrm{NH} 4^{+}-\mathrm{N}$ concentration was decreased quickly after aerating for $120 \mathrm{~min}$.It mainly due to the low COD load in the system. Until 270 min, the nitrification was finished.The degradation of organic matter in R1 was delayed 30 min than 
R2.So after aerating $150 \mathrm{~min}$, the organic in system became undegradated, and nitrification began. $\mathrm{NH}_{4}{ }^{+}-\mathrm{N}$ concentration decreased until 330min. Then the concentration maintains in this arrange.

After aeration, $\mathrm{NH}^{+}-\mathrm{N}$ keeps about $8.1 \mathrm{mg} / \mathrm{L}$ in $\mathrm{R} 1,6.2 \mathrm{mg} / \mathrm{L}$ in $\mathrm{R} 2$. Obviously, the efficiency of nitrogen removal in $\mathrm{R} 2$ was $7 \%$ highly than R1. So it can be got the conclusion that the humus soil contributs to the performance, it makes the nitrification accomplish completely and shorten the aeation time and improve the efficiency of $\mathrm{NH}_{4}{ }^{+}-\mathrm{N}$ removal.

Figure 4 shows the profile of $\mathrm{NO}_{3}^{-}-\mathrm{N}$ and $\mathrm{NO}_{2}{ }^{-}-\mathrm{N}$ in $\mathrm{R} 1$ and $\mathrm{R} 2$. The NO3--N concentration increased after $150 \mathrm{~min}$ in $\mathrm{R} 1,120 \mathrm{~min}$ in $\mathrm{R} 2$. The quantity of increased $\mathrm{NO}_{3}{ }^{-} \mathrm{N}$ is less than the degree of decreased $\mathrm{NH}_{4}{ }^{+}-\mathrm{N}$, especially in $\mathrm{R} 2$. In R2, from $120 \mathrm{~min}$ to $240 \mathrm{~min}, \mathrm{NH}_{4}{ }^{+}-\mathrm{N}$ changed $17.0 \mathrm{mg} / \mathrm{L}$, but $\mathrm{NO}_{3}{ }^{-}-\mathrm{N}$ changed $9.1 \mathrm{mg} / \mathrm{L}$. The phenomence also can be observed in $\mathrm{R} 1$. All the phenomence suggested that SND (Simul taneous Nitrification and Denitrification). In SND, the sdsorbed organic matter was used by denitrification bacteria and the denitrification was accomplished in aeration conditions.

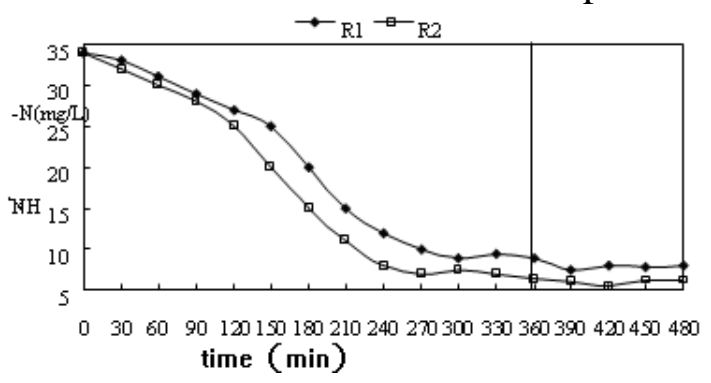

Fig. 3 The profile of NH3-N in R1 and R2 SBR reactor

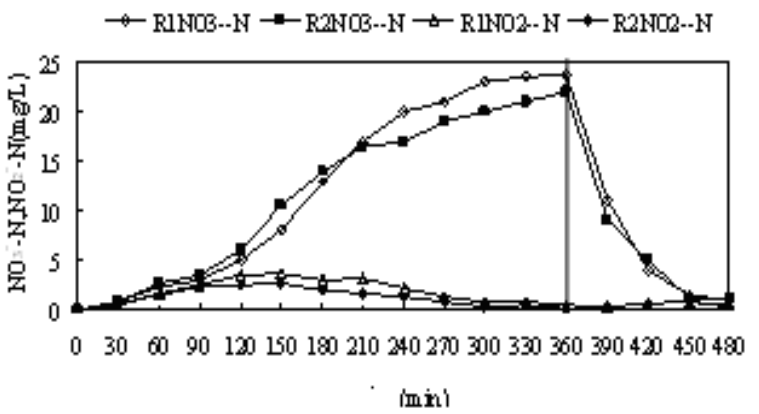

Fig.4 The profile of NO3--N and NO2--N in R1 and R2 SBR reactor

\subsection{The quantities of microbial community in R1 and R2}

To detail the difference of the microbial commununity in two biological processes, nitrification bacteria was chosen to be detected. The results shows that (1) There's no nitrobacteria in blank sample. (2) There's no nitrobacteria in R1 and R2's raw water. (3) The nitrobacteria numbers in R1 shows in table 2. (4) The nitrobacteria numbers in R2 shows in table 3.

Table 2. MPN for nitrobacteria in R1

\begin{tabular}{|c|c|c|}
\hline Diluted concentration & Tubes that bacteria grew inside & Quantitive index \\
\hline $10^{-1}$ & 3 & 3 \\
\hline $10^{-2}$ & 3 & 3 \\
\hline $10^{-3}$ & 2 & 2 \\
\hline $10^{-4}$ & 0 & 0 \\
\hline $10^{-5}$ & 1 & 1 \\
\hline $10^{-6}$ & 0 & 0 \\
\hline $10^{-7}$ & 0 & 0 \\
\hline $10^{-8}$ & 0 & 0 \\
\hline $10^{-9}$ & 0 & 0 \\
\hline $10^{-10}$ & 0 & 0 \\
\hline
\end{tabular}

From Table 1, quantitive index is 32 1. Approximate value is 15.0.So the nitrobacteria numbers of the sample R1 is $1.5 \times 10^{3} \mathrm{cfu} / \mathrm{ml}$. 
From Table 2, quantitive index is 330 . approximate value is 25.0 . So the nitrobacteria numbers of the sample R2 is $2.5 \times 10^{8} \mathrm{cfu} / \mathrm{ml}$.The numbers of nitrobacteria in R2 is 100,000 times in R1.The results show that the quantities of nitrification bacteria in HASP was obvousily highly than Conventional Activated Sludge Process, it mainly because of the humus activated sludge can accumulate the growth of the microorganism, the feed also can provide the space for the growth.According to metabolism, the nitrogen can be removal, the organic, phusphorus and the odor can be decleared. This is the reason why the time of the nitrification can be shorten and the nitrification efficiency can be improved.

Table 3. MPN for nitrobacteria in R2

\begin{tabular}{|c|c|c|}
\hline Diluted concentration & Tubes that bacteria grew inside & Quantitive index \\
\hline $10^{-1}$ & 3 & 3 \\
\hline $10^{-2}$ & 3 & 3 \\
\hline $10^{-3}$ & 3 & 3 \\
\hline $10^{-4}$ & 0 & 0 \\
\hline $10^{-5}$ & 2 & 2 \\
\hline $10^{-6}$ & 2 & 2 \\
\hline $10^{-7}$ & 3 & 3 \\
\hline $10^{-8}$ & 3 & 3 \\
\hline $10^{-9}$ & 0 & 0 \\
\hline $10^{-10}$ & 0 & 0 \\
\hline
\end{tabular}

\section{Conclusion}

In this study, Humus Activated sludge process was applied to treat domestic sewage comparing with conventional activated sludge process. As a result, the new process exhibited superior process performance. It has superior efficiency of nitrogen removal and the reaction time was shorten. According to the investigating, the quantity of the nitrification bacteria, the Humus Activated Sludge Process indicates special characteristics. It makes the bacteria reproduce quickly and the quantity was increased more quickly than R1. This regular was the similar as the regular of nitrogen removal.

\section{Acknowledgements}

This work was financially supported by the science and technology projects of Jilin province education department (No.532, 2016) and Jilin province college students' innovative entrepreneurial training program (3370).

\section{References}

[1]. Huck PM. Measurement of biodegradable organic matter and bacterial growth potential in drinking water[ J]. JAWWA, 1990, 82(7): 78-86.

[2]. ShiJialuo,XuYatong,ZhangShengzhang,etc.Environ-mental Microbiology [M].Shanghai: East China Normal university Publishing house, 1993

[3]. Wen Suying,Gu Zuyi.Environmental Microbiology [M].Beijing: Scientific Publishing house,1985

[4]. Qiu Wenfang. Environmental Microbiology-a laboratory manual [M]. Beijing:XueYuan Publishing house, 1989

[5]. He Yanling,Chen Aixia. Environmental Microbiology [M]. Beijing: Chinese Light industry Publishing house, 2001

[6]. Zhou Qunying,Gao Yaoting Environmental Microbiology.(2rd edition) [M]. Beijing: Eleevier academic press, 2000 